\title{
The MAKE Biomarker Discovery for Enhancing anTidepressant Treatment Effect and Response (MAKE BETTER) Study: Design and Methodology
}

\author{
Hee-Ju Kang', Ju-Wan Kim¹, Seon-Young Kim², Sung-Wan Kim¹, \\ Hee-Young Shin ${ }^{3}$, Myung-Geun $\mathrm{Shin}^{4}$, and Jae-Min Kim ${ }^{1 凶}$ \\ 1'Department of Psychiatry, Chonnam National University Medical School, Gwangju, Republic of Korea \\ ${ }^{2}$ Mental Health Clinic, Chonnam National University Hwasun Hospital, Hwasun, Republic of Korea \\ ${ }^{3}$ Department of Biomedical Science, Chonnam National University Medical School, and Clinical Trial Center, Chonnam National University Hospital, \\ Gwangju, Republic of Korea \\ ${ }^{4}$ Department of Laboratory Medicine, Chonnam National University Medical School, Gwangju, Republic of Korea
}

Objective Depression is associated with a major disease burden, and many individuals suffer from depressive symptoms due to an insufficient response to ostensibly adequate antidepressant treatment. Therefore, it is important to identify reliable treatment response predictors for use in developing personalized treatment strategies.

Methods The MAKE Biomarker discovery for Enhancing anTidepressant Treatment Effect and Response (MAKE BETTER) study was performed to identify predictors of antidepressant response using a 2-year naturalistic prospective design. Participants in the MAKE BETTER study were consecutively recruited from patients who visited the Psychiatry Department of Chonnam National University Hospital, Gwangju, South Korea for treatment of a depressive disorder. Data on demographic and clinical characteristics, genetic markers measured by whole-exome sequencing, and blood markers were obtained. The types and doses of antidepressants were determined based on the clinical judgment of the psychiatrist, and the treatment outcomes (e.g., depressive and other psychiatric symptoms and issues related to safety) were assessed.

Results We will be able to use the data collected in this study to develop a treatment-response prediction index composed of biomarkers. Conclusion The MAKE BETTER study will provide an empirical basis for a personalized medicine approach to depression by enabling the prediction of antidepressant treatment response according the characteristics of each patient. It will thereby support evidencebased decision-making that decreases the use of a trial-and-error approach to the treatment of depressive disorders.

Psychiatry Investig 2018;15(5):538-545

Key Words Biological marker, Depression, Observational study, Predictors, Treatment response.

\section{INTRODUCTION}

\section{Disease burden and unmet treatment needs associated with depression}

Depression, which is already common, is expected to be the leading contributor to the global disease burden by $2030 .^{1}$

Received: June 16, 2017 Revised: August 10,2017

Accepted: October 2, 2017

$\triangle$ Correspondence: Jae-Min Kim, MD, PhD

Department of Psychiatry, Chonnam National University Medical School, 160 Baekseo-ro, Dong-gu, Gwangju 61469, Republic of Korea

Tel: +82-62-220-6143, Fax: +82-62-225-2351

E-mail: jmkim@chonnam.ac.kr

(a) This is an Open Access article distributed under the terms of the Creative Commons Attribution Non-Commercial License (http://creativecommons.org/licenses/bync/4.0) which permits unrestricted non-commercial use, distribution, and reproduction in any medium, provided the original work is properly cited.
Moreover, suicide, a life-threatening potential outcome of depression, constitutes a major public health problem. Antidepressant medications have made important contributions to the treatment of depression, including reducing the morbidity and costs associated with this disorder. ${ }^{2}$ However, it has been estimated that one-third ${ }^{3}$ to two-thirds ${ }^{4}$ of patients receive insufficient benefits from an ostensibly adequate regimen of a first-line antidepressant medication. Moreover, research has also reported that $15-33 \%$ of this group do not respond to multiple interventions. ${ }^{5,6}$ Until now, the most effective antidepressant for individual patients has been identified by trial and error, leading to delays in recovery and poor outcomes, including disability and compromised quality of life. Therefore, it has become important to identify reliable treat- 
ment response predictors for use in developing personalized treatment strategies for depressive disorders.

\section{Role of biomarkers in predicting and enhancing antidepressant response}

Decades of research have been devoted to efforts to identify the biomarkers and underlying biological mechanisms associated with antidepressant response for use in tailoring medication regimens to each patient's biological profile. Research has been oriented toward identifying biomarkers involving protein levels and genetic variations using candidate gene and genome-wide association studies (GWAS).

\section{Genetic markers}

Genetic markers are thought to be reliable biomarkers for antidepressant response, given that genetic markers cannot be changed during depressive episodes or the treatment process. ${ }^{8}$ Considerable effort has been devoted to determining the best genetic markers with which to identify individuals who are most likely to benefit from particular antidepressants with the fewest adverse effects. Candidate gene studies have reported relatively consistent findings, and a recent meta-analysis suggested that the brain-derived neurotrophic factor (BDNF) val/met polymorphism and the polymorphism related to serotonergic systems that include a variable number of tandem repeats within intron 2 (STin2), a serotonin transporter gene promoter polymorphism (5-HTTLPR), and a serotonin receptor (HTR2a) polymorphism, were associated with antidepressant response and adverse effects. ${ }^{9}$ Unfortunately, the effect of individual polymorphisms has been too small to affect clinical decisions about antidepressants.

\section{GWAS}

GWAS have been performed to predict responses to antidepressants in an effort to compensate for the disappointing results of candidate gene studies. Six GWAS have investigated antidepressant responses in Western ${ }^{10-12}$ and Asian populations. ${ }^{13-15}$ However, although one study found genome-wide significant variations, ${ }^{13}$ the other studies, including a metaanalysis of 2,256 individuals from three Western studies, ${ }^{16}$ failed to find meaningful genome-wide significance levels. Moreover, the results of individual studies did not overlap. Based on the inconclusive and unreplicated findings from the GWAS, larger sample sizes are needed to detect significant associations in GWAS. Additionally, given that a substantial part of the genetic vulnerability associated with antidepressant response may not be accounted for by the variants usually measured in these studies, it seems clear that other genetic data using different genetic platforms are needed to determine reliable genetic markers.

\section{Whole-exome sequencing}

The use of human genome sequencing enables identification of the genetic variants that affect heritable phenotypes and drug sensitivity. Indeed, application of whole-exome sequencing to investigation of all the exons of the protein-coding genes in the genome has made it possible to identify previously uncharacterized polymorphisms that determine antidepressant response. ${ }^{17}$ However, only one such study has been conducted, and this research had a limited sample size ( $\mathrm{n}=10$ depressed patients) and evaluated only one antidepressant (escitalopram). ${ }^{18}$

\section{Protein markers}

Protein markers are useful complements to genetic information, given that they are the outputs of gene translation that reflect the actual functional status of and effects of the environment on the organism. A number of studies have investigated alterations in neurotrophic factors, the hypothalamuspituitary-adrenal (HPA) axis, and inflammatory systems.

Given that a previous meta-analysis found that the level of $\mathrm{BDNF}$ is decreased in patients with depression and increases with the clinical improvements associated with the use of antidepressants, it has been suggested that of the neurotrophic factors, BDNF, which affects neuronal plasticity, can serve as a reliable biomarker for antidepressant response. ${ }^{19,20}$ Although this meta-analysis found that the restoration of BDNF levels was more prominent in responders than in non-responders, ${ }^{21}$ and although an individual study found that responders had higher pre-treatment BDNF levels than non-responders, ${ }^{22}$ questions about whether BDNF can serve as a predictive biomarker for antidepressant response remain unanswered, rendering these findings of no clinical utility in psychiatric practice.

Abnormality in the HPA axis, one of the most commonly reported biological alterations in depression, may be a candidate predictor of treatment response. In general, depressed patients exhibit HPA axis hyperactivity ${ }^{23,24}$ that seems to decrease after antidepressant treatment. ${ }^{25}$ However, some evidence suggests that persistent HPA axis hyperactivity during antidepressant treatment is predictive of a relapse of major depressive disorder (MDD) ${ }^{26,27}$ Nevertheless, in the context of these inconsistent findings, no consensus has been established regarding whether the parameters of the HPA axis have predictive value for the treatment response of depressed patients. ${ }^{24,28}$

Recent evidence suggests that major depression is associated with inflammation, including higher concentrations of inflammatory markers [e.g., C-reactive protein, interleukin (IL)-1, and IL-6], ${ }^{29,30}$ and findings indicating that such inflammation may be modified with antidepressants has drawn research attention to the inflammatory system as a potential 
biomarker of antidepressant response. ${ }^{31} \mathrm{~A}$ recent meta-analysis found that treatment non-responders tended to have higher levels of baseline inflammation, ${ }^{32}$ but it also reported a lack of significant results regarding the necessary composites of inflammatory markers.

\section{Limitations of previous studies, future directions, and the MAKEBETTER study}

Despite years of research focused on identifying reliable predictors of treatment response, no such predictor has been identified thus far. Clinical and sociodemographic characteristics have revealed weak predictive value, although recent challenges combining 48 predictors have increased prediction accuracy up to $77.7 \% .{ }^{33}$ No biomarkers or genetic markers have been established despite recent trials to determine the additive effects of individual single-nucleotide polymorphisms (SNPs) and to integrate GWAS data with extant (albeit disappointing) findings. ${ }^{34}$ Previous studies appear to have had limited ability to determine whether individual predictors represent clinical or genetic phenomena. Research has demonstrated that the heritability of antidepressant response can reach $40 \%,{ }^{35}$ which is the same level associated with clinical and environmental markers; thus, genetic markers alone are not sufficient to predict treatment responses in cases of depression. Moreover, GWAS with inadequate samples have been unable to identify the predictors of antidepressant response.

Therefore, we designed the MAKE BETTER study to investigate the integrated markers needed to predict treatment response in patients with depressive disorder. This study focused on a comprehensive array of clinical data and genetic and other protein biomarkers to increase the predictive power of our model to a clinically useful level. Our use of a naturalistic prospective design allowed for broad inclusion and minimal exclusion criteria to reflect real clinical situations. To overcome the limitations of previous genetic marker studies, we adopted a whole-exome sequencing approach to identify the genetic factors that influence antidepressant treatment response. Based on comprehensive data from the MAKE BETTER study, we will be able to determine the most significant markers for predicting treatment response. Additionally, by applying appropriate bioinformatics techniques, we will develop a treatment response prediction index based on a list of biomarkers and their estimated power for predicting treatment response.

\section{METHODS}

\section{Study design and recruitment}

The MAKE BETTER study is an ongoing effort to explore the biomarkers for antidepressant treatment response among individuals with depressive disorders. This study has been supported by the Korean Ministry of Health and Welfare since 2012 and by the Basic Science Research Program through the National Research Foundation of Korea (NRF), funded by the Ministry of Science, ICT and Future Planning, since 2016. To identify the biomarkers for predicting treatment responses in real-world settings, we employed a naturalistic prospective study design rather than randomized controlled trials, as the latter assessed treatment responses under ideal conditions including rigorous controls. Therefore, treatment decisions would not be influenced by the study protocol, rendering the results reflective of actual clinical practice. Moreover, no prohibited drugs were existed, and the kind, dose, and maintenance duration of antidepressants were based on the clinician's judgment. Participants were consecutively recruited from patients with depressive disorder who had recently visited the Psychiatry Department of Chonnam National University Hospital, Gwangju, Korea. Patients with depressive symptoms were clinically evaluated for depressive symptoms by study psychiatrists using the Mini-International Neuropsychiatric Interview (MINI), a structured diagnostic psychiatric interview based on DSM-IV criteria. ${ }^{36}$ Eligible patients with depressive disorders who agreed to participate in the MAKE BETTER study were approached for follow-up assessments at 1,2, 3, and 6 weeks; 3 months; and every 3 months thereafter up to 2 years to determine the short- and long-term treatment outcomes and clinical course of their depressive disorder. We approached those depressed patients who participated in the MAKE BETTER study who were free from psychotropic medication for at least 1 month to participate in an additional study, the Cortisol study, which was designed to determine the role of endocrinological biomarkers in treatment response prediction; to that end, we collected salivary samples from those who agreed to participate. Written informed consent forms were obtained for both studies, and both studies were approved by the Chonnam National University Hospital Institutional Review Board (CNUH 2012-014).

\section{Study subjects}

Both inpatients and outpatients who met the appropriate inclusion and exclusion criteria were asked to participate in the MAKE BETTER and cortisol studies (Table 1). Figure 1 presents the size of each sample. We hypothesized that patients with a partial or absent response to antidepressant medication would require a minimum of four stages of treatment based on our determination that this approach would yield an $80 \%$ power to detect a 0.45 effect size for the primary outcome [treatment response as defined as a Hamilton Rating Scale for Depression (HAMD) score reduction of $>50 \%$ over 


\begin{tabular}{|c|c|}
\hline MAKE BETTER study & Cortisol study \\
\hline \multicolumn{2}{|l|}{ Inclusion criteria } \\
\hline Aged older than 7 years & Same as the MAKE BETTER study but \\
\hline DSM IV diagnoses of major depressive disorder, dysthymic disorder, and depressive & Aged older than 20 years \\
\hline disorder not otherwise specified (NOS) as ascertained by the MINI & Free of psychotropic medications for at least \\
\hline Score $\geq 14$ on the Hamilton Depression Rating Scale & 1 month \\
\hline $\begin{array}{l}\text { Female patients with child-bearing potential who did not plan to become pregnant } \\
\text { during the study period and agreed to use an appropriate contraceptive method }\end{array}$ & \\
\hline Able to complete the questionnaires & \\
\hline Able to understand the objective of the study and sign informed consent form & \\
\hline \multicolumn{2}{|l|}{ Exclusion criteria } \\
\hline Unstable or uncontrolled medical condition & Same as the MAKE BETTER study \\
\hline \multicolumn{2}{|l|}{$\begin{array}{l}\text { Unable to complete the psychiatric assessment or comply with the medication regimen } \\
\text { due to a severe physical illness }\end{array}$} \\
\hline \multicolumn{2}{|l|}{$\begin{array}{l}\text { Current or lifetime DSM-IV diagnosis of bipolar disorder, schizophrenia, } \\
\text { schizoaffective disorder, schizophreniform disorder, psychotic disorder NOS, } \\
\text { or other psychotic disorders }\end{array}$} \\
\hline \multicolumn{2}{|l|}{ History of organic psychosis, epilepsy, or seizure disorder } \\
\hline \multicolumn{2}{|l|}{ History of anticonvulsant treatment } \\
\hline \multicolumn{2}{|l|}{$\begin{array}{l}\text { Hospitalization for any psychiatric diagnosis except depressive disorder (e.g., alcohol/ } \\
\text { drug dependence) }\end{array}$} \\
\hline \multicolumn{2}{|l|}{ Electroconvulsive therapy for the current depressive episode } \\
\hline Pregnant or breastfeeding & \\
\hline
\end{tabular}

MAKE BETTER: MAKE Biomarker discovery for Enhancing anTidepressants Treatment Effect and Response, DSM-IV: Diagnostic and Statistical Manual 4th edition, MINI: Mini-International Neuropsychiatric Interview

the treatment period] using chi-square tests with statistical significance set at 0.05 . Given a previously reported followup loss rate of $45 \%$ in a Korean naturalistic study of antidepressant trials, a minimum of 39 subjects per group and 1,136 subjects in total were needed.

\section{Treatment}

Depressed patients were managed by the study psychiatrists according to the practice guidelines for the treatment of patients with major depressive disorder (MDD). ${ }^{37,38}$ Specifically, monotherapy with first-line antidepressants was applied for 2-4 weeks. Patients with a partial or absent response were either switched to another antidepressant, or adjunctive medications, including antipsychotics, lithium, thyroid hormones, or other antidepressants, were prescribed according to the treatment guidelines. Patients who experienced improvement were provided with maintenance treatment for 6-24 months based on the individual risk for recurrence.

\section{Assessment}

All patients who participated in the MAKE BETTER and cortisol studies completed a baseline assessment as well as 12 follow-up assessments performed over a period of 2 years. To compensate for the limitations of previous studies in which limited numbers of candidate markers for antidepressant re- sponse were investigated, this study tried to evaluate a comprehensive array of clinical data and genetic and other protein biomarkers. During the baseline evaluation, we collected data on a variety of factors that potentially affect responses to antidepressants, including sociodemographic, clinical, and biological characteristics; characteristics subject to change were also assessed during the follow-up period. Table 2 summarizes the detailed evaluation schedules.

\section{Clinical assessment}

All patients underwent a diagnostic evaluation, including assessments of medical and psychiatric histories, conducted by study psychiatrists. Lifetime and current DSM-IV diagnoses of axis I disorders were determined using a structured diagnostic psychiatric interview, the MINI, and the severity of depression was determined using the 17-item HAMD to confirm eligibility for study participation. ${ }^{39}$ Additional assessments were performed by two research nurses who were blind to the HAMD and MINI findings.

General sociodemographic (i.e., gender, age, educational level, marital status, occupation, socioeconomic status, personal and family history of psychiatric and physical illnesses, and gynecological history) and psychological (personality type, social support, and stress) information was collected. Personality was evaluated using the 10 -item short version of 


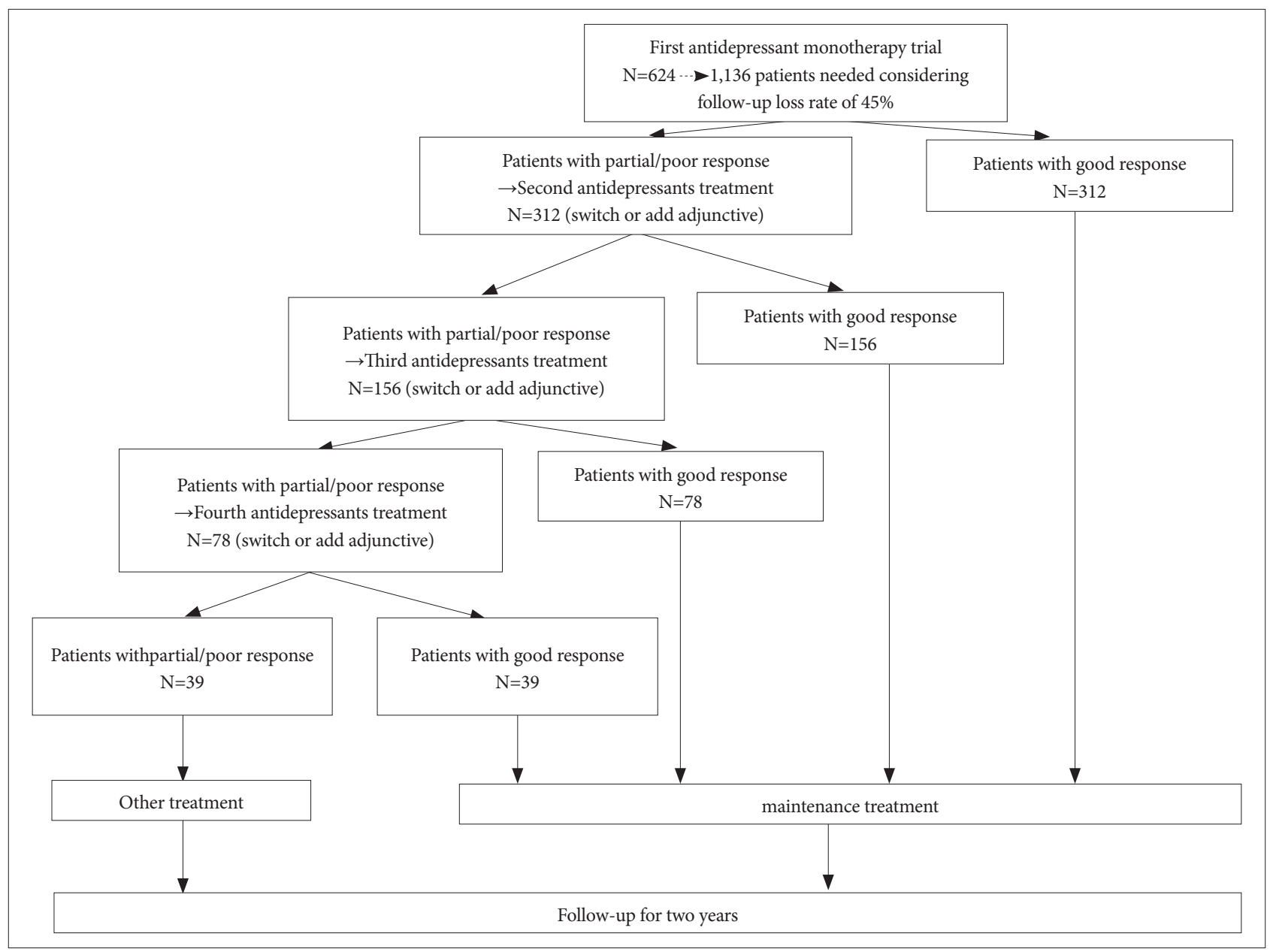

Figure 1. Sample size according to treatment process.

the Big Five Inventory. ${ }^{40}$ Social support deficits were measured with the Multidimensional Scale of Perceived Social Support. ${ }^{41}$ The assessment of stress included the number of stressful life events (SLEs), subjective perceptions of stress, and level of resilience. The number of SLEs was determined using the modified Korean version of the Life Experiences Survey, which includes 37 items on stressful events within the previous 3 months. ${ }^{42}$ Adverse experiences before the age of 16 years were assessed with four items assessing physical, psychological, and sexual abuse. Perceptions of stress were evaluated with the Perceived Stress Scale, ${ }^{43}$ and the ability to cope with stressful events was measured using the Conner-Davidson Resilience Scale. ${ }^{44}$

To evaluate the severity of depressive symptoms, we administered additional measures, including the Hospital Anxiety and Depression Scales (HADS) ${ }^{45}$ and the Clinical Global Impression Scale-severity (CGI-s). ${ }^{46}$ Thus, three depression scales were used to measure depression severity: the HAMD, which is the observer-rated scale most widely used in clinical trials on depression treatment outcomes; the HADS, which is a self-reported measure with fewer items addressing the somatic manifestations of depression; and the CGI-s, which is a brief assessment of general symptomatology. ${ }^{47}$

To assess other psychiatric symptoms included in our multidimensional conceptualization of depression and treatment outcomes, we assessed psychological wellbeing and functioning, functional disability, suicidality, and quality of life. Functional disability was measured with the Social and Occupational Functioning Assessment Scale (SOFAS) ${ }^{48}$ and the Sheehan Disability Scale (SDS). ${ }^{49}$ Suicidality was evaluated with the suicide-related items on the Brief Psychiatric Rating Scale (BPRS), ${ }_{, 0}^{50}$ and the Schedule for Affective Disorders and Schizophrenia (SADS).$^{51}$ Health-related quality of life was assessed with the EuroQol-5 Dimension (EQ-5D). ${ }^{52}$

\section{Biological assessment}

Blood samples were collected from participants at both baseline and the 1-year follow-up visit to identify the biological markers for predicting antidepressant response as well as to analyze changes during the treatment period as a function of 
Table 2. Schedule of assessment for MAKE BETTER study

\begin{tabular}{|c|c|c|c|c|c|c|c|c|c|c|c|c|}
\hline Assessments & Base-line & $\begin{array}{c}1 \\
\text { weeks } \\
\end{array}$ & $\begin{array}{c}2 \\
\text { weeks } \\
\end{array}$ & $\begin{array}{c}3 \\
\text { weeks } \\
\end{array}$ & $\begin{array}{c}6 \\
\text { weeks } \\
\end{array}$ & $\begin{array}{c}3 \\
\text { Month } \\
\end{array}$ & $\begin{array}{c}6 \\
\text { Month } \\
\end{array}$ & $\begin{array}{c}12 \\
\text { Month } \\
\end{array}$ & $\begin{array}{c}15 \\
\text { Month } \\
\end{array}$ & $\begin{array}{c}18 \\
\text { Month } \\
\end{array}$ & $\begin{array}{c}21 \\
\text { Month } \\
\end{array}$ & $\begin{array}{c}24 \\
\text { Month } \\
\end{array}$ \\
\hline \multicolumn{13}{|l|}{ Clinical assessment } \\
\hline Socio-demographic characteristics & $\sqrt{ }$ & & & & & & & & & & & \\
\hline \multicolumn{13}{|l|}{ Psychological characteristics } \\
\hline Personality & $\sqrt{ }$ & & & & & $\sqrt{ }$ & & $\sqrt{ }$ & & & & \\
\hline Social support & $\sqrt{ }$ & & & & & $\sqrt{ }$ & & $\sqrt{ }$ & & & & $\sqrt{ }$ \\
\hline Stress-related status & $\sqrt{ }$ & & & & & $\sqrt{ }$ & & $\sqrt{ }$ & & & & $\sqrt{ }$ \\
\hline \multicolumn{13}{|l|}{ Outcomes of depression } \\
\hline Depressive symptom & $\sqrt{ }$ & $\sqrt{ }$ & $\sqrt{ }$ & $\sqrt{ }$ & $\sqrt{ }$ & $\sqrt{ }$ & $\sqrt{ }$ & $\sqrt{ }$ & $\sqrt{ }$ & $\sqrt{ }$ & $\sqrt{ }$ & $\sqrt{ }$ \\
\hline Functional disability & $\sqrt{ }$ & $\sqrt{ }$ & $\sqrt{ }$ & $\sqrt{ }$ & $\sqrt{ }$ & $\sqrt{ }$ & $\sqrt{ }$ & $\sqrt{ }$ & $\sqrt{ }$ & $\sqrt{ }$ & $\sqrt{ }$ & $\sqrt{ }$ \\
\hline Suicidality & $\sqrt{ }$ & $\sqrt{ }$ & $\sqrt{ }$ & $\sqrt{ }$ & $\sqrt{ }$ & $\sqrt{ }$ & $\sqrt{ }$ & $\sqrt{ }$ & $\sqrt{ }$ & $\sqrt{ }$ & $\sqrt{ }$ & $\sqrt{ }$ \\
\hline Quality of life & $\sqrt{ }$ & $\sqrt{ }$ & $\sqrt{ }$ & $\sqrt{ }$ & $\sqrt{ }$ & $\sqrt{ }$ & $\sqrt{ }$ & $\sqrt{ }$ & $\sqrt{ }$ & $\sqrt{ }$ & $\sqrt{ }$ & $\sqrt{ }$ \\
\hline \multicolumn{13}{|l|}{ Biological assessment } \\
\hline Blood biomarker & $\sqrt{ }$ & & & & & & & $\sqrt{ }$ & & & & \\
\hline Salivary cortisol (cortisol study only) & $\sqrt{ }$ & & $\sqrt{ }$ & & $\sqrt{ }$ & $\sqrt{ }$ & $\sqrt{ }$ & & & & & \\
\hline Electrocardiography & $\sqrt{ }$ & & & & & & & $\sqrt{ }$ & & & & \\
\hline Resting BP, body mass index & $\sqrt{ }$ & & $\sqrt{ }$ & & $\sqrt{ }$ & $\sqrt{ }$ & $\sqrt{ }$ & $\sqrt{ }$ & $\sqrt{ }$ & $\sqrt{ }$ & $\sqrt{ }$ & $\sqrt{ }$ \\
\hline \multicolumn{13}{|l|}{ Treatment related assessment } \\
\hline Antidepressants, dosage, duration & $\sqrt{ }$ & $\sqrt{ }$ & $\sqrt{ }$ & $\sqrt{ }$ & $\sqrt{ }$ & $\sqrt{ }$ & $\sqrt{ }$ & $\sqrt{ }$ & $\sqrt{ }$ & $\sqrt{ }$ & $\sqrt{ }$ & $\sqrt{ }$ \\
\hline Adverse events & $\sqrt{ }$ & $\sqrt{ }$ & $\sqrt{ }$ & $\sqrt{ }$ & $\sqrt{ }$ & $\sqrt{ }$ & $\sqrt{ }$ & $\sqrt{ }$ & $\sqrt{ }$ & $\sqrt{ }$ & $\sqrt{ }$ & $\sqrt{ }$ \\
\hline Withdrawal & $\sqrt{ }$ & $\sqrt{ }$ & $\sqrt{ }$ & $\sqrt{ }$ & $\sqrt{ }$ & $\sqrt{ }$ & $\sqrt{ }$ & $\sqrt{ }$ & $\sqrt{ }$ & $\sqrt{ }$ & $\sqrt{ }$ & $\sqrt{ }$ \\
\hline
\end{tabular}

MAKE BETTER: MAKE Biomarker discovery for Enhancing anTidepressants Treatment Effect and Response, BP: blood pressure

treatment course. Considering the unsatisfactory results of previous genetic marker studies using the genome-wide association approach, we adopted a new approach to identify the genetic factors that influence antidepressant treatment responses. We investigated genetic markers via whole-exome sequencing; blood biomarkers, including those for neuronal plasticity; neuroendocrine markers associated with the HPA axis; immunological markers, including cytokine levels; and biomarkers of one-carbon metabolism. Additionally, we evaluated data on vital signs, body mass index, and electrocardiography (ECG) variables. Saliva samples were collected from those who participated in the cortisol study to assess the cortisol awakening response at baseline, 2, 6, 12, and 24 weeks. Participants in the cortisol study were instructed to collect saliva samples at home using Salivettes (Sarstedt AG and Co, Nümbrecht, Germany) at three time points (at awakening, at 30 minutes after awakening, and at $10 \mathrm{PM}$ ) during the day before the assessment schedule.

\section{Treatment-related assessment}

The HAMD was used as the primary outcome measure for assessing antidepressant response, and other depression measures, including the HADS and CGI-s, were used as second- ary outcome measures. Other psychiatric outcome measures included the SOFAS, SDS, EQ-5D, and BPRS/SADS. All scales were administered at baseline and at every follow-up visit. In terms of general safety, adverse events during the study period were recorded at all visits. Serious clinical and laboratory adverse events were assessed using blood samples and ECG at both baseline and the 1-year follow-up visit. Resting blood pressure (BP) was measured at baseline and at 2 weeks, 6 weeks, and every 3 months for 2 years during follow-up visits. Discontinuation of participation in the study due to adverse events was recorded.

\section{Development of a treatment response prediction index}

After the last enrolled subject has been followed for 2 years, we will integrate the comprehensive data obtained via the MAKE BETTER study. The most significant markers for predicting treatment response will be identified using statistical methods. Furthermore, by applying appropriate bioinformatics techniques, we will develop a treatment response prediction index based on a list of biomarkers; we will then calculate the estimated predictive power of the index with regard to treatment response. Following the validation of our treatment prediction index, we hope to use it to prescribe antide- 
pressants in clinical practice; this should result in increasing treatment response and decreasing adverse effects, leading to improvements in recovery and better outcomes for depressed patients.

\section{CONCLUSION}

The MAKE BETTER study will make a meaningful and significant contribution to research on the prediction of antidepressant response. Compared to previous studies, the prospective naturalistic study design of our research will yield data that reflect actual clinical practice and, in turn, the findings of our study will enhance our understanding of relevant issues. Our use of a novel genetic testing technology, whole genome sequencing, will enable us to identify the genetic variants related to treatment response and thereby contribute to the development of an innovative antidepressant response prediction index. Moreover, our data on predictors of antidepressant response according to individual characteristics, such as genetic vulnerabilities, blood level status, and related interactions, should provide guidance for decision-making about choice of antidepressant, serving as a cornerstone of precision medicine in psychiatry.

\section{Acknowledgements}

This study was supported by a grant of the Korean Health Technology R\&D Project, Ministry of Health \& Welfare, Republic of Korea (HI12C0003) to J.M. Kim and supported by Basic Science Research Program through the National Research Foundation of Korea (NRF) funded by the Ministry of Science, ICT and future Planning (NRF-2016R1C1B2006793) to H.J. Kang. The funders had no role in study design; in the collection, analysis and interpretation of data; in the writing of the report; or in the decision to submit the paper for publication.

\section{REFERENCES}

1. World Health Organization. The Global Burden of Disease: 2004 Update. Geneva: WHO Press; 2008.

2. World Health Organization. Chapter 2: Burden of mental and behavioral disorders. In the World health report 2001-Mental health: New Understanding, New hope Impact of disorders. Available at http:// www.who.int/whr/2001/en/whr01_chr2_en.pdf. Accessed June 6, 2017.

3. Al-Harbi KS. Treatment-resistant depression: therapeutic trends, challenges, and future directions. Patient Prefer Adherence 2012;6:369-388.

4. Jenkins E, Goldner EM. Approaches to understanding and addressing treatment-resistant depression: a scoping review. Depress Res Treat 2012;2012:469680

5. Trivedi MH, Fava M, Wisniewski SR, Thase ME, Quitkin F, Warden D, et al. Medication augmentation after the failure of SSRIs for depression. New Engl J Med 2006;354:1243-1252.

6. Berlim MT, Fleck MP, Turecki G. Current trends in the assessment and somatic treatment of resistant/refractory major depression: an overview. Ann Med 2008;40:149-159.

7. Steimer W, Müller B, Leucht S, Kissling W. Pharmacogenetics: a new diagnostic tool in the management of antidepressive drug therapy. Clin Chim Acta 2001;308: 33-41.

8. McMahon FJ. Clinically useful genetic markers of antidepressant response: how do we get there from here? Am J Psychiatry. 2015;172:697-
699.

9. Kato M, Serretti A. Review and meta-analysis of antidepressant pharmacogenetic findings in major depressive disorder. Mol Psychiatry 2010;15:473-500.

10. Ising M, Lucae S, Binder EB, Bettecken T, Uhr M, Ripke S, et al. A genomewide association study points to multiple loci that predict antidepressant drug treatment outcome in depression. Arch Gen Psychiatry 2009;66:966-975.

11. Garriock HA, Kraft JB, Shyn SI, Peters EJ, Yokoyama JS, Jenkins, GD, et al. A genomewide association study of citalopram response in major depressive disorder. Biol Psychiatry 2010;67:133-138.

12. Uher R, Perroud N, Ng MY, Hauser J, Henigsberg N, Maier W, et al. Genome-wide pharmacogenetics of antidepressant response in the GENDEP project. Am J Psychiatry 2010;167:555-564 .

13. Myung W, Kim J, Lim SW, Shim S, Won HH, Kim S, et al. A genomewide association study of antidepressant response in Koreans. Transl Psychiatry 2015;5:e633.

14. Biernacka JM, Sangkuhl K, Jenkins G, Whaley RM, Barman P, Batzier A, et al. The International SSRI Pharmacogenomics Consortium (ISPC): a genome-wide association study of antidepressant treatment response. Transl Psychiatry 2015;5:e553.

15. Sasayama D, Hiraishi A, Tatsumi M, Kamijima K, Ikeda M, Umene-Nakano W, et al. Possible association of CUX1 gene polymorphisms with antidepressant response in major depressive disorder. Pharmacogenomics J 2013;13:354-358.

16. GENDEP Investigators, MARS Investigators, $S T A{ }^{\star} D$ Investigators. Common genetic variation and antidepressant efficacy in major depressive disorder: A meta-analysis of three genome-wide pharmacogenetic studies. Am J Psychiatry 2013;170:207-217.

17. Holsboer F. How can we realize the promise of personalized antidepressant medicines? Nat Rev Neurosci 2008;9:638-646.

18. Tammiste A, Jiang T, Fischer K, Mägi R, Krjutškov K, Pettai K, et al. Whole exome sequencing identifies a polymorphism in the BMP5 gene associated with SSRI treatment response in major depression. J Psychopharmacol 2013;27:915-920.

19. Brunoni AR, Lopes M, Fregni F. A systematic review and meta-analysis of clinical studies on major depression and BDNF levels: implications for the role of neuroplasticity in depression. Int J Neuropsychopharmacol 2008;11:1169-1180.

20. Fernandes BS, Berk M, Turck CW, Steiner J, Goncalves CA. Decreased peripheral brain-derived neurotrophic factor levels are a biomarker of disease activity in major psychiatric disorders: a comparative metaanalysis. Mol Psychiatry 2014;19:750-751.

21. Polyakova M, Stuke K, Schuemberg K, Mueller K, Schoenknecht P, Schroeter ML. BDNF as a biomarker for successful treatment of mood disorders: a systematic \& quantitative meta-analysis. J Affect Disord 2015; 174:432-440

22. Wolkowitz OM, Wolf J, Shelly W, Rosser R, Burke HM, Lerner GK, et al. Serum BDNF levels before treatment predict SSRI response in depression. Prog Neuropsychopharmacol Biol Psychiatry 2011;35:1623-1630.

23. Vreeburg SA, Kruijtzer BP, van Pelt J, van Dyck R, DeRijk RH, Hoogendijk WJ, et al. 2009. Associations between sociodemographic, sampling and health factors and various salivary cortisol indicators in a large sample without psychopathology. Psychoneuroendocrinology 2009;34:1109-1120.

24. Lok A, Mocking RJ, Ruhé HG, Visser I, Koeter MW, Assies J, et al. Longitudinal hypothalamic-pituitary-adrenal axis trait and state effects in recurrent depression. Psychoneuroendocrinology 2012;37:892-902

25. Ruhé HG, Khoenkhoen SJ, Ottenhof KW, Koeter MW, Mocking RJ, Schene AH. Longitudinal effects of the SSRI paroxetine on salivary cortisol in Major Depressive Disorder. Psychoneuroendocrinology 2015;52:261-271.

26. Hardeveld F, Spijker J, Vreeburg SA, Graaf R, Hendriks SM, Licht CM, et al. Increased cortisol awakening response was associated withtime to recurrence of major depressive disorder. Psychoneuroendocrinolo- 
gy 2014;50:62-71.

27. Binder E. The role of FKBP5: a co-chaperone of the glucocorticoid receptor in the pathogenesis and therapy of affective and anxiety disorders. Psychoneuroendocrinology 2009;34(Suppl 1):S186-S195.

28. Bockting CL, Lok A, Visser I, Assies J, Koeter MW, Schene AH. Lower cortisol levels predict recurrence in remitted patients with recurrent depression: a 5.5 year prospective study. Psychiatry Res 2012;200:281-287.

29. Howren MB, Lamkin DM, Suls J. Associations of depression with Creactive protein, IL-1, and IL-6: a meta-analysis. Psychosom Med 2009;71:171-186.

30. Valkanova V, Ebmeier KP, Allan CL. CRP, IL-6 and depression: a systematic review and meta-analysis of longitudinal studies. J Affect Disord 2013;150:736-744.

31. Hannestad J, DellaGioia N, Bloch M. The effect of antidepressant medication treatment on serum levels of inflammatory cytokines: a metaanalysis. Neuropsychopharmacology 2011;36:2452-2459.

32. Strawbridge R, Arnone D, Danese A, Papadopoulos A, Herane Vives A, Cleare AJ. Inflammation and clinical response to treatment in depression: a meta-analysis. Eur Neuropsychopharmacol 2015;25:1532-1543.

33. Kautzky A, Baldinger-Melich P, Kranz GS, Vanicek T, Souery D, Montgomery S, et al. A new prediction model for evaluating treatment-resistant depression. J Clin Psychiatry 2017;78:215-222.

34. García-González J, Tansey KE, Hauser J, Henigsberg N, Maier W, Mors $\mathrm{O}$, et al. Pharmacogenetics of antidepressant response: a polygenic approach. Prog Neuropsychopharmacol Biol Psychiatry 2017;75:128-134.

35. Tansey KE, Guipponi M, Hu X, Domenici E, Lewis G, Malafosse A, et al. Contribution of common genetic variants to antidepressant response. Biol Psychiatry 2013;73:679-682.

36. Sheehan DV, Lecrubier Y, Sheehan KH, Amorim P, Janavs J, Weiller E, et al. The mini-international neuropsychiatric interview (M.I.N.I): the development and validation of a structured diagnostic psychiatric interview for DSM-IV and ICD-10. J Clin Psychiatry 1998;59 (Suppl 20): S22-S33.

37. Kennedy SH, Lam RW, McIntyre RS, Tourjman SV, Bhat V, Blier P, et al. Canadian Network for Mood and Anxiety Treatments (CANMAT) 2016 Clinical Guidelines for the Management of Adults with Major Depressive Disorder: Section 3. Pharmacological Treatments. Can J Psychiatry 2016;61:540-560.
38. American Psychiatric Association. Treating Major Depressive Disorder; Practice Guideline for the treatment of patients with major depressive disorder, Third Ed; 2010. Available at http://psychiatryonline.org/ $\mathrm{pb} /$ assets/raw/sitewide/practive_guidellines/guidelines/mdd.pdf. Accessed June 6, 2017.

39. Hamilton M. A rating scale for depression. J Neurol Neurosurg Psychiatry 1960;23:56-62.

40. Rammstedt B, John OP. Measuring personality in one minute or less: A 10-item short version of the Big Five Inventory in English and German. J Res Pers 2007;41:203-212.

41. Zimet, GD, Dahlem NW, Zimet SG. The multidimensional scale of perceived social support. J Pers Assess 1988;52:30-41.

42. Lee YH. Relations Between Attributional Style, Life Events, Event Attribution, Hopelessness and Depression. Thesis. Seoul: Seoul National University PhD; 1993.

43. Cohen S, Kamarck T, Mermelstein R. A Global Measure of Perceived Stress. J Health Soc Behav 1983;24:385-396.

44. Connor KM, Davidson JR. Development of a new resilience scale: the Connor-Davidson Resilience Scale (CD-RISC). Depress Anxiety 2003; 18:76-82.

45. Guy W. ECDEU Assessment Manual for Psychopharmacology. Revised. Rockville: National Institute of Mental Health; 1976

46. Zigmond AS, Snaith RP. The Hospital Anxiety and Depression Scale. Acta Psychiatr Scand 1983;67:361-370.

47. Salter K, Bhogal SK, Foley N, Jutai J, Teasell R. The assessment of poststroke depression. Top Stroke Rehabil 2007;14:1-24.

48. American Psychiatric Association. Diagnostic and Statistical Manual of Mental Disorders, 4th Ed. Washington, DC: American Psychiatric Press Inc; 1994.

49. Sheehan DV. The Anxiety Disease. New York: Charles Scribner Sons; 1983.

50. Overall JE, Gorham DR. The brief psychiatric rating scale. Psychol Rep 1962;10:799-812.

51. Endicott J, Spitzer RL. A diagnostic interview: the Schedule for affective disorders and schizophrenia. Arch Gen Psychiatry 1978;35:873-844.

52. Rabin R, de Charro F. EQ-5D: a measure of health status from the EuroQol Group. Ann Med 2001;33:337-343. 